\title{
Synergistic Action of Cyclic Adenosine Monophosphate- and Calcium-mediated Chloride Secretion in a Colonic Epithelial Cell Line
}

\author{
Christine A. Cartwright, James A. McRoberts, Kenneth G. Mandel, and Kiertisin Dharmsathaphorn
}

Department of Medicine, University of California, San Diego, California 92103

\begin{abstract}
Vasoactive intestinal polypeptide (VIP) and the calcium ionophore A23187 caused dose-dependent changes in the potential difference and the short circuit current $\left(I_{\mathbf{s c}}\right)$ across confluent $T_{84}$ cell monolayers mounted in modified Ussing chambers. Both VIP and A23187 stimulated net chloride secretion without altering sodium transport. Net chloride secretion accounted for the increase in $I_{a c}$. When $\mathbf{A 2 3 1 8 7}$ was tested in combination with VIP, net chloride secretion was significantly greater than predicted from the calculated sum of their individual responses indicating a synergistic effect. VIP increased cellular cyclic AMP (cAMP) production in a dose-dependent manner, whereas A23187 had no effect on cellular cAMP. We then determined whether VIP and A23187 activated different transport pathways. Earlier studies suggest that VIP activates a basolaterally localized, barium-sensitive potassium channel as well as an apically localized chloride conductance pathway. In this study, stimulation of basolateral membrane potassium efflux by $\mathbf{A 2 3 1 8 7}$ was documented by preloading the monolayers with ${ }^{86} \mathbf{R b}^{+}$. Stimulation of potassium efflux by A23187 was additive to the VIP-stimulated potassium efflux. By itself, $0.3 \mu \mathrm{M}$ A23187 did not alter transepithelial chloride permeability, and its stimulation of basolateral membrane potassium efflux caused only a relatively small amount of chloride secretion. However, in the presence of an increased transepithelial chloride permeability induced by VIP, the effectiveness of $A 23187$ on chloride secretion was greatly augmented. Our studies suggest that CAMP and calcium each activate basolateral potassium channels, but cAMP also activates an apically localized chloride channel. Synergism results from cooperative interaction of potassium channels and the chloride channel.
\end{abstract}

\section{Introduction}

Cyclic nucleotides and calcium are well recognized as intracellular messengers. Evidence is accumulating for interaction between these messengers, resulting in potentiation of cellular response. In many systems, these interactions may serve as a mechanism to prepare the cell for a biological response and to facilitate the amplification of a hormonal signal, allowing the amplification to be accomplished by the release of a small amount of peptide hormones or neurotransmitters. The synergistic phenomena between cyclic AMP (cAMP)- and calciummediated electrolyte secretion have not been reported in isolated intestine. In other gastrointestinal organ systems, e.g., the pan-

Address reprint requests to Dr. Dharmsathaphorn.

Received for publication 20 February 1985.

J. Clin. Invest.

(C) The American Society for Clinical Investigation, Inc.

$0021-9738 / 85 / 11 / 1837 / 06 \quad \$ 1.00$

Volume 76, November 1985, 1837-1842 creatic exocrine or endocrine cells and gastric parietal cells, the synergistic action between CAMP- and calcium-mediated responses has been established. A secretagogue which mobilizes cellular calcium (carbachol, cholecystokinin, bombesin, or the calcium ionophore A23187) potentiates the action of a secretagogue that acts through, or mimics the action of cAMP (vasoactive intestinal polypeptide [VIP], ${ }^{1}$ secretin, or 8-Br-AMP) on amylase secretion from dispersed pancreatic acini of rat and guinea pig $(1,2)$. Dibutyryl cAMP in combination with carbachol or A23187 amplifies enzyme secretion from rat pancreas $(3,4)$. Insulin release by pancreatic islets also exhibits a synergistic response to agents which increase intracellular cAMP and calcium (5). Histamine (cAMP mediated) and carbarchol potentiate gastric acid secretion in isolated canine parietal cells (6).

Despite the lack of direct evidence of synergism between cAMP- and calcium-mediated secretory mechanisms in the intestine, there is evidence that indirectly suggests the existence of such a phenomenon. Many antisecretagogues, (e.g., somatostatin, enkephalin), which may act through a calcium-mediated mechanism, inhibit the secretory process almost totally whether they are induced by a calcium-dependent process (e.g., serotonin) or cAMP-mediated process (e.g., VIP). Presumably, due to the presence of preexisting VIP, acetylcholine, etc., in whole or isolated intestine, activation of the secretory process by a secretagogue would readily result in a synergistic response. It is possible that the preexisting peptides or neurotransmitters make it difficult to detect a potentiative effect. The synergistic action of cAMP and calcium in the stomach and pancreas could be demonstrated easier and more convincingly in isolated cell preparations than in whole organs. Isolated cells devoid of preexisting peptide hormones or neurotransmitters may allow the effect of each compound to be assessed individually or in combination without the confounding effect of other existing peptides or neurotransmitters. We therefore, chose a cultured colonic epithelial cell line, $\mathrm{T}_{\mathbf{8 4}}$, as a model system to study the interaction of cAMPand calcium-mediated electrolyte secretion. The cell line, which consists only of epithelial cells, has the advantage of isolated cell preparations. More importantly, the fact that $\mathrm{T}_{84}$ cells form confluent monolayers with intact tight junctions allows measurement of vectorial electrolyte transport similar to the use of isolated intestine and thus allows comparison of the results. Such a model system may facilitate the investigation of a relatively complex function of intestinal epithelial cells. In this study, VIP was used as a representative of cAMP-mediated secretagogues. VIP binds epithelial cells, activates adenylate cyclase and CAMP production, and stimulates net chloride secretion (7-14). Similar responses to VIP were observed in the $\mathrm{T}_{84}$ epithelial monolayers, assuring the suitability of this model for the study of VIP action. A23187 was used as an example of a calcium-mediated secre-

1. Abbreviations used in this paper: $I_{\mathrm{sc}}$, short circuit current; VIP, vasoactive intestinal polypeptide. 


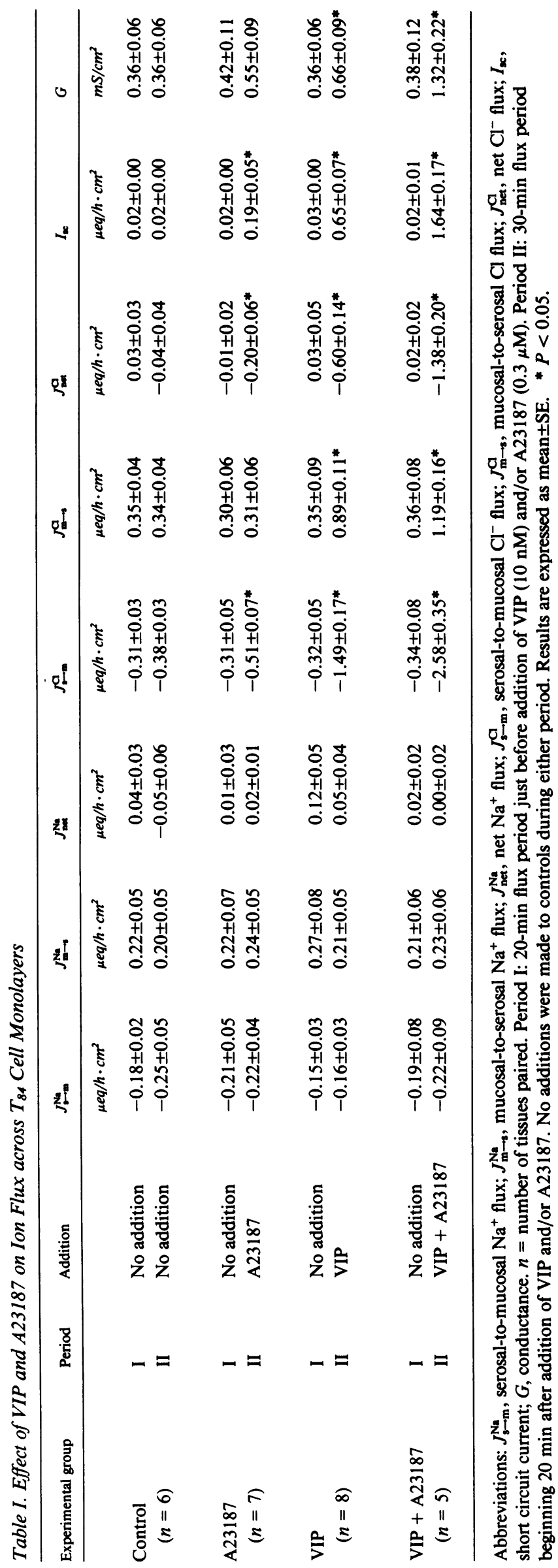

tagogue. The compound, which is known to stimulate net chloride secretion in intact intestinal epithelium, also causes chloride secretion in $\mathrm{T}_{84}$ cell monolayers (15-17). In this report, utilizing the $T_{84}$ cell line, we first demonstrated that $A 23187$ potentiates VIP-induced chloride secretion, and then investigated the basis for the synergistic response.

\section{Methods}

Growth and maintenance of $T_{84}$ cells, transepithelial electrolyte transport studies, ${ }^{86} \mathrm{Rb}^{+}$efflux studies, and measurement of cAMP follow procedures similar to those described in the preceding article (18).

${ }^{125} \mathrm{I}$-VIP binding studies. Binding of ${ }^{125} \mathrm{I}-\mathrm{VIP}$ to dispersed $\mathrm{T}_{84}$ cells was determined at room temperature using a procedure described previously (7). At appropriate time intervals after adding $10^{-10} \mathrm{M}^{125} \mathrm{I}$-VIP to the incubating media containing dispersed $T_{84}$ cells, triplicate $100-\mu 1$ samples were layered over $300 \mu \mathrm{l}$ of ice-cold wash solution and centrifuged at $10,000 \mathrm{~g}$ for $30 \mathrm{~s}$ in a Beckman Microfuge (Beckman Instruments, Inc., Palo Alto, CA). The cells were resuspended in $300 \mu \mathrm{l}$ of wash solution and centrifuged at $10,000 \mathrm{~g}$ for another $30 \mathrm{~s}$, the wash procedure requiring 2-3 min. Binding of ${ }^{125} \mathrm{I}-\mathrm{VIP}$ was expressed as a percentage of that present in the incubation medium.

Materials. All radionuclides were obtained from New England Nuclear, Boston, MA. VIP was generously supplied by Dr. Jean Rivier, The Salk Institute, La Jolla, CA. A23187 was purchased from Behring Diagnostics, La Jolla, CA; carbachol from ICN Pharmaceuticals, Plainview, NY, and prostaglandin $E_{1}$ from the Upjohn Co., Kalamazoo, MI.

Statistical analysis. Student's $t$ test and analysis of variance were used to determine the difference (19).

\section{Results}

\section{Sodium and chloride transport}

The results of unidirectional and net sodium and chloride movement are summarized in Table $I$ and Fig. $1 . T_{84}$ monolayers, when mounted in modified Ussing chambers, maintained stable conductance and a constant rate of transcellular sodium and chloride flux throughout the study period of $\sim 2 \mathrm{~h}$. Unidirectional flux of sodium and chloride, short circuit current $\left(I_{\mathrm{sc}}\right)$, and transepithelial conductance measured in control tissues during period I (control period) were identical to values measured in period II (experimental period).

Effect of VIP. Addition of $10 \mathrm{nM}$ VIP to the serosal bath caused an increase in $I_{\mathrm{sc}}$ and net chloride secretion (Fig. $1 \mathrm{~A}$ ), while mucosal addition had no effect (data not shown). Net chloride flux correlated well with, and totally accounted for, the increase in $I_{\mathrm{sc}}(r=0.90 ; P<0.001)$. After $10 \mathrm{nM}$ VIP addition, both serosal-to-mucosal chloride $\left(J_{\mathrm{s} \rightarrow \mathrm{m}}^{\mathrm{C}}\right)$ and mucosal-to-serosal chloride movement $\left(J_{\mathrm{m} \rightarrow \mathrm{s}}^{\mathrm{Cl}}\right)$ increased significantly, suggesting an increase in chloride permeability. The increase in $J_{s \rightarrow m}^{\mathrm{Cl}}$ was consistently greater than the increase in $J_{\mathrm{m} \rightarrow \mathrm{s}}^{\mathrm{C}}$, resulting in net $\mathrm{Cl}^{-}$ secretion. In contrast to the effect on chloride secretion, $10 \mathrm{nM}$ VIP has no significant effect on unidirectional or net sodium transport. Conductance increased with the addition of VIP. Similar $I_{\mathrm{sc}}$ responses were observed with the addition of $10 \mathrm{nM}$ cholera toxin or $100 \mu \mathrm{M}$ dibutyryl cAMP (data not shown).

Effect of A23187. The effect of A23187 on $I_{s c}$ was dose dependent; a maximal response was observed with $2 \mu \mathrm{M}$ A23187 (Fig. 2). $0.3 \mu \mathrm{M} \mathrm{A23187,} \mathrm{a} \mathrm{threshold} \mathrm{concentration,} \mathrm{induced} \mathrm{a}$ small net chloride secretion which completely accounted for the increase in $I_{s c}$ (Fig. $1 \mathrm{~B}$ ). The effect of $0.3 \mu \mathrm{M}$ A23187 on transepithelial electrolyte fluxes resembles that with VIP with some differences. After A23187 addition, $J_{s \rightarrow \mathrm{m}}^{\mathrm{Cl}}$ increased but $J_{\mathrm{m} \rightarrow \mathrm{s}}^{\mathrm{Cl}}$ re- 


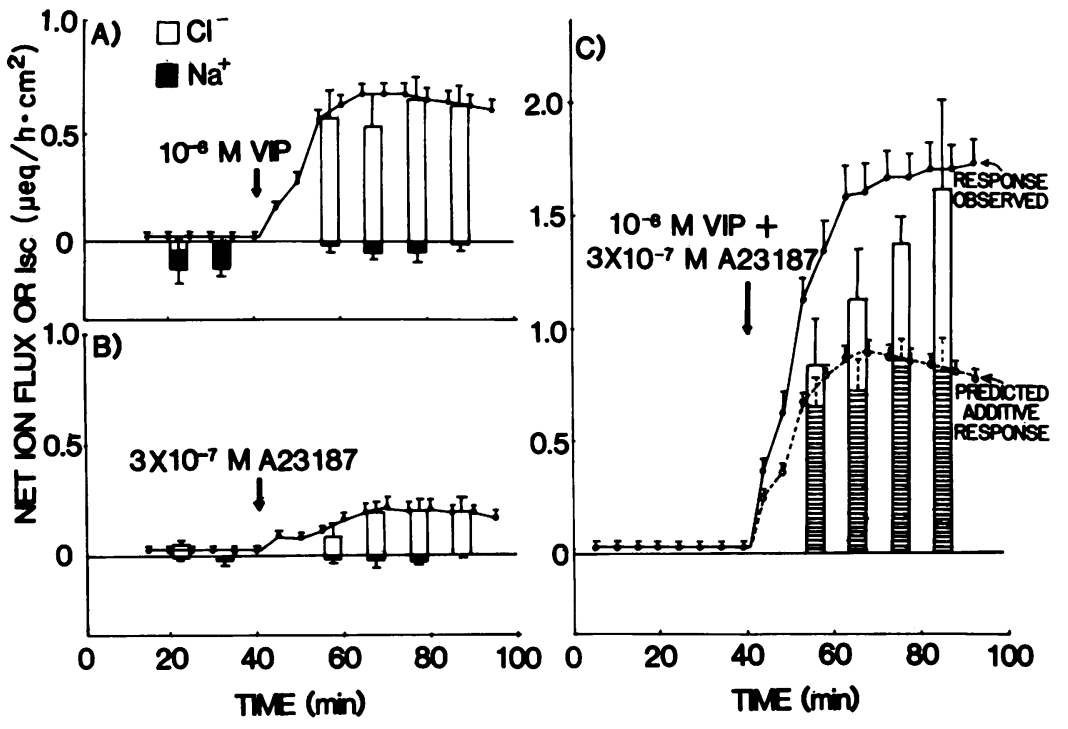

Figure 1. Time course of the effect of VIP $(A)$, A23187 (B), and VIP plus A23187 $(C)$ on net ion transport and $I_{\mathrm{sc}}$ across $\mathrm{T}_{84}$ cell monolayers (grown on collagen-coated Nuclepore filters as described in Methods). Open bars represent net $\mathrm{Cl}^{-}$transport and solid bars, net $\mathrm{Na}^{+}$transport over a 10 -min flux period. Circles and lines represent $I_{\mathrm{sc}}$. In $C$, the hatched bars, open circles, and dashed line represent the predicted additive response from results shown in $A$ and $B$. Results are expressed as mean $\pm \mathrm{SE}$ in microequivalents per hour per square centimeter; values above the line represent net secretion and those below the line, net absorption. Results of unidirectional flux conductances and the number of tissue pairs $(n)$ are summarized in Table $\mathrm{I}$. mained unaltered, resulting in net chloride secretion which was relatively small. No change in $J_{\mathbf{s} \rightarrow \mathrm{m}}^{\mathrm{Na}}$ or $J_{\mathrm{m} \rightarrow \mathrm{s}}^{\mathrm{Na}}$ was observed. A similar effect was observed with A23187 at higher concentrations of 1 or $2 \mu \mathrm{M}$. At these concentrations which give maximal response, net chloride secretion remained relatively small as compared to the response of VIP (14). It should be noted that the conductance of the monolayers also increased with the addition of A23187. This increase was more dramatic with monolayers grown on collagen gel for $3 \mathrm{~d}$, which had a high conductance to start with, and probably accounted for the high $I_{\text {sc }}$ response observed in Fig. 2.

Effect of both VIP and A23187. When a threshold concentration of A23187 $(0.3 \mu \mathrm{M})$ was tested in combination with a concentration of VIP that gave a maximal response (10 nM), the resulting net chloride secretion was not only higher than that could be maximally induced by VIP but was significantly greater than predicted from the calculated sum of their individual responses (Fig. $1 C$ ). Unindirectional ion fluxes, summarized in Table I, showed the increase in $J_{\mathrm{s} \rightarrow \mathrm{m}}^{\mathrm{Cl}}$ exceeds $J_{\mathrm{m} \rightarrow \mathrm{s}}^{\mathrm{Cl}}$ after the addition of both VIP and A23187, resulting in net chloride secretion. The increase in $J_{s \rightarrow m}^{\mathrm{Cl}}$ induced by both VIP and A23187 was significantly greater than that induced by VIP alone, whereas $J_{\mathrm{m} \rightarrow \mathrm{s}}^{\mathrm{Cl}}$ increased to the same level. Again, no change in $J_{\mathrm{s} \rightarrow \mathrm{m}}^{\mathrm{Na}}$ or $J_{\mathrm{m} \rightarrow \mathrm{s}}^{\mathrm{Na}}$ was observed after addition of both VIP and A23187. It should be noted that the change in $I_{\text {sc }}$ could be accounted for by net chloride secretion. The conductance of the monolayers

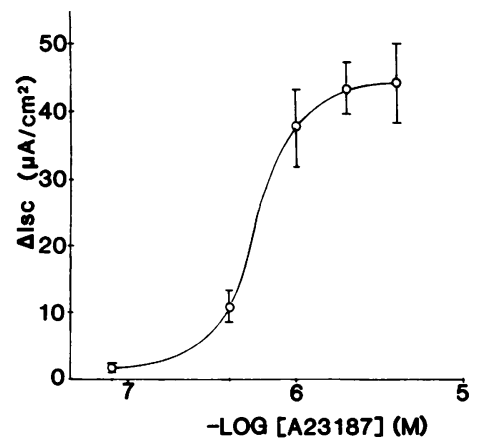

Figure 2. Graded dose effect of A23187 on $I_{\mathrm{sc}}$ across $\mathrm{T}_{84}$ cell monolayers (grown on collagen gels as described in Methods). Each monolayer had a surface area of 1.98 $\mathrm{cm}^{2}$. A23187 was added 25 min after mounting. Values represent the change in $I_{s c}$ in microamperes per square centimeter $25 \mathrm{~min}$ after A23187 addition. Each point represents the

mean \pm SE of six to eight monolayers. Only one concentration of A23187 was added to each monolayer. increased with the addition of both VIP and A23187. When 0.3 $\mu \mathrm{M}$ A23187 was tested in combination with varying concentrations of VIP, the increase in $I_{\mathrm{sc}}$ was significantly greater than predicted from the calculated sum of their individual responses throughout a wide range of VIP concentrations (from $0.1 \mathrm{nM}$ to $0.1 \mu \mathrm{M}$ ) (Fig. 3).

Effect of other cAMP- and calcium-mediated secretagogues. To test whether the potentiation phenomenon is limited to VIP and A23187, we studied the changes in $I_{s c}$ induced by VIP or prostaglandin $E_{1}$ and carbachol. The action of prostaglandin $E_{1}$ in intestinal mucosal is known to be cAMP dependent $(20,21)$; while that of carbachol, calcium dependent (22). The response to prostaglandin $E_{1}$ and carbachol of $T_{84}$ cells appears to be qualitatively similar to those reported in isolated intestine (12). In this study, we also observed synergism between carbachol and VIP or prostaglandin $\mathrm{E}_{1}$ actions. The peak $I_{\mathrm{sc}}$ response of $10 \mathrm{nM}$ VIP, $10 \mu \mathrm{M}$ prostaglandin $\mathrm{E}_{1}$, and $0.1 \mathrm{mM}$ carbachol alone were $44 \pm 11,44 \pm 6$, and $34 \pm 6 \mu \mathrm{A}$ per monolayer, respectively. The combination of $0.1 \mathrm{mM}$ carbachol and $10 \mathrm{nM}$ VIP

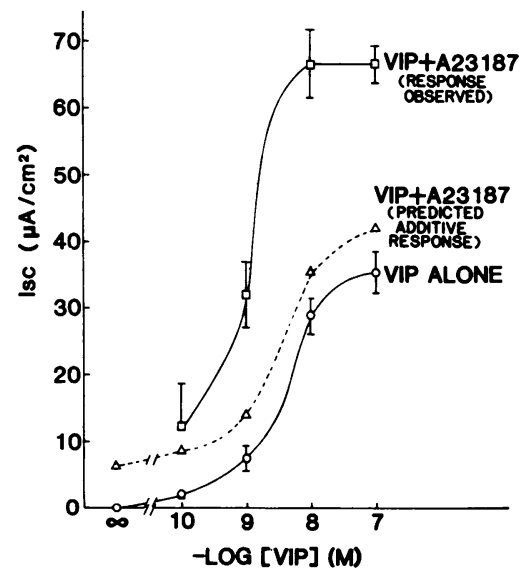

Figure 3. Graded dose effect of VIP and VIP plus A23187 $\left(3 \times 10^{-7}\right.$ $\mathrm{M})$ on $I_{\mathrm{sc}}$ across $T_{84}$ cell monolayers (grown on collagen gels). The surface area of each monolayer was $1.98 \mathrm{~cm}^{2}$. VIP, alone or in combination with A23187, was added 25 min after mounting. Values represent the mean $\pm \mathrm{SE}$ of the changes in $I_{\mathrm{sc}}$ in microamperes per square centimeter 25 min after additions from six to eight monolayers. Only one concentration of VIP and A23187 was added to each monolayer. 
or $10 \mu \mathrm{M}$ prostaglandin $\mathrm{E}_{1}$ caused a peak $I_{\mathrm{sc}}$ increase of $135 \pm 18$ $\mu \mathrm{A}$ per monolayer and $103 \pm 13 \mu \mathrm{A}$ per monolayer, respectively ( $n=5$ in all groups). These results are greater than the additive effect and are indicative of a synergistic action.

\section{cAMP measurements and ${ }^{125}$ I-VIP receptor binding assays}

Assays for cAMP and VIP receptors were carried out to determine whether the synergism between VIP and A23187 was related to cellular cAMP production and to confirm that the action of VIP was mediated by cAMP. Although every attempt was made to keep the conditions of cAMP assays and $I_{\mathrm{sc}}$ measurements identical, a different binding condition of ${ }^{125} \mathrm{I}$-VIP binding was necessary to optimize specific binding. After $10 \mathrm{~min}$ of incubation with $10^{-8} \mathrm{M}$ VIP at room temperature, cAMP had increased maximally and remained constant during the subsequent $30 \mathrm{~min}$ of incubation whereas maximal $I_{\mathrm{sc}}$ response and ${ }^{125} \mathrm{I}-\mathrm{VIP}$ binding were achieved after $20 \mathrm{~min}$ of incubation (data not shown). The graded dose effect of VIP on competitive binding of ${ }^{125} \mathrm{I}$-VIP, cAMP production, and on the increase in $I_{\mathrm{sc}}$ were determined after 25-min incubations when all of them were at their maximal levels. The results are summarized in Fig. 4. VIP caused a dose-dependent increase in cAMP in $\mathrm{T}_{84}$ cells. A small increase in cAMP could be detected with $1 \mathrm{nM}$ VIP and maximal stimulation occurred with $10 \mathrm{nM}$ VIP. A23187 (0.3-2.5 $\mu \mathrm{M})$ did not affect cAMP production in $\mathrm{T}_{84}$ cells and the presence of A23187 did not affect the increase in cAMP by VIP (14). The dose-dependent curves for VIP were identical in the presence or absence of $0.3 \mu \mathrm{M}$ A23187, indicating that cAMP was not the basis for synergism and suggesting that A23187 potentiated the action of VIP at a step distal to the production of cellular cAMP. ${ }^{125}$ I-VIP binding correlated well with cAMP production and the increase in $I_{\mathrm{sc}}$. Increasing concentrations of VIP inhibited the binding of ${ }^{125} \mathrm{I}-\mathrm{VIP}$, and increased cAMP production and $I_{\mathrm{sc}}$ to a very similar magnitude. The half-maximal inhibition of ${ }^{125} \mathrm{I}$-VIP binding occurred with $5 \mathrm{nM}$ VIP and half-maximal stimulation of both cAMP and $I_{\mathrm{sc}}$ was observed with $4 \mathrm{nM}$ VIP. The results strongly suggest that the action of VIP is mediated by cAMP.

\section{Rubidium efflux experiments}

We have previously demonstrated that both VIP and A23187 stimulated potassium (and rubidium) efflux across the basolateral

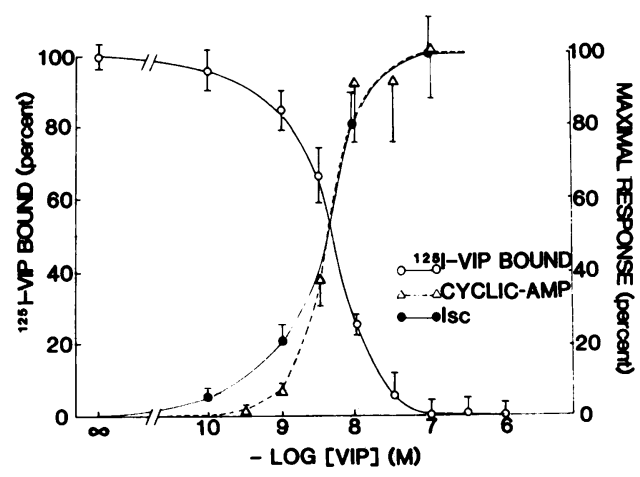

Figure 4. Comparison of competitive binding curve of ${ }^{125}$ I-VIP, cellular cAMP production, and $I_{\mathrm{sc}}$ response at varying concentrations of VIP. Values represent mean \pm SE of three to eight measurements. The scales were adjusted to $100 \%$ for comparison. Maximal binding of ${ }^{125} \mathrm{I}$ VIP was $6.5 \pm 0.2 \%$ with nonspecific binding being $3.9 \pm 0.1 \%$. Maximal cAMP level was $348 \pm 51 \mathrm{pmol} / \mathrm{mg}$ of protein with basal cAMP level being $3 \pm 1 \mathrm{pmol} / \mathrm{mg}$ of protein. Maximal $I_{\mathrm{sc}}$ response was $73 \pm 8 \mu \mathrm{A} /$ $\mathrm{cm}^{2}$ with basal $I_{\mathrm{sc}}$ being zero. surface of the $T_{84}$ cells and that this potassium recycling mechanism may be intimately involved in the chloride secretory process $(14,23,24)$. In another study, VIP was found to increase chloride uptake and efflux across the apical membrane whereas a similar effect was not observed with A23187 (25). This part of the study was designed to quantitate the magnitude of potassium efflux across the basolateral membrane caused by VIP and/ or A23187 and determine whether the potassium efflux across the basolateral membrane can explain the synergistic action of VIP and A23187. Utilizing the Ussing chamber and monolayers preloaded with ${ }^{86} \mathrm{Rb}^{+}$, we were able to determine simultaneously ${ }^{86} \mathrm{Rb}^{+}$efflux rates across both the apical and basolateral membranes of $\mathrm{T}_{84}$ monolayers while monitoring the change in $I_{\mathrm{sc}}$ that reflects changes in chloride secretion. ${ }^{86} \mathrm{Rb}^{+}$was used as a tracer for potassium transport, in part because of the difficulty in dealing with the short half-life of ${ }^{42} \mathrm{~K}^{+}$, and also because prolonged exposure to ${ }^{42} \mathrm{~K}^{+}$significantly decreased the transepithlial resistance and the integrity of the monolayers. In another study in which ${ }^{42} \mathrm{~K}^{+}$and ${ }^{86} \mathrm{Rb}^{+}$uptake and efflux were compared, the results were quite similar, indicating that ${ }^{86} \mathrm{Rb}^{+}$is a suitable tracer for potassium in the $T_{84}$ cell line (24). Results from these efflux studies along with the mean $I_{s c}$ and transcellular conductance for each of two time intervals in which additions of VIP and/or A23187 were made, are tabulated in Table II. The basal $I_{\mathrm{sc}}$ and changes in $I_{\mathrm{sc}}$ in response to VIP and A23187 were similar to previous results that indicated that chloride secretory mechanisms remained intact after ${ }^{86} \mathrm{Rb}^{+}$preincubation. Under a shortcircuited condition, the basal rate of ${ }^{86} \mathrm{Rb}^{+}$efflux into the mucosal bath was more than an order of magnitude smaller than that into the serosal bath. The addition of $10 \mathrm{nM}$ VIP or $0.3 \mu \mathrm{M}$ A23187 (which were added to both sides) increased the rate of ${ }^{86} \mathrm{Rb}^{+}$efflux into the serosal bath by approximately twofold, while the rate of ${ }^{86} \mathrm{Rb}^{+}$efflux into the mucosal bath was not affected. It should be noted that at the concentration of VIP used $(10 \mathrm{nM}$, which was the concentration that gives a maximal response), there was a significant increase in $I_{\text {sc }}$ (which reflected net chloride secretion) as well as an increase in the conductance of the monolayers (which probably reflected an increase in chloride conductance). In contrast, at the concentration of A23187 used, $(0.3 \mu \mathrm{M}$, which was the threshold concentration for a response), the increase in $I_{\mathrm{sc}}$ was minimal or barely detectable and there was no increase in the conductance of the monolayers. These findings indicate that there was only little stimulation of chloride secretion by $\mathrm{A} 23187$ at the concentration used. However, potassium efflux across the basolateral membrane was stimulated by $0.3 \mu \mathrm{M}$ A23187 to approximately the same level as that induced by $10 \mathrm{nM}$ VIP. We have previously shown that a higher concentration of A23187 caused a greater increase in potassium efflux but the magnitude of chloride secretion was relatively small as compared to those induced by VIP, suggesting that the chloride transport pathway on the apical membrane may be a rate-limiting step for the action of A23187 (14). Carbachol, which increases free cytosolic calcium, also had a very similar action as compared to A23187 (26). The results of this study showed that the increase in ${ }^{86} \mathrm{Rb}^{+}$was additive in the presence of both VIP and A23187, whereas the magnitude of chloride secretion was more than additive.

\section{Discussion}

The $T_{84}$ cells retain many receptor-mediated processes and respond to a variety of secretagogues, including VIP and A23187, by secreting chloride similar to isolated intestine (12). In this 


\begin{tabular}{|c|c|c|c|c|c|c|}
\hline \multirow[b]{2}{*}{ Experimental group } & \multirow[b]{2}{*}{ Period } & \multirow[b]{2}{*}{ Addition } & \multicolumn{2}{|c|}{${ }^{86} \mathrm{Rb}^{+}$efflux rate constant } & \multirow[b]{2}{*}{$I_{\mathrm{sc}}$} & \multirow[b]{2}{*}{$G$} \\
\hline & & & Mucosal & Serosal & & \\
\hline & & & $h^{-1}$ & $h^{-1}$ & $\mu \mathrm{A} / \mathrm{cm}^{2}$ & $\mathrm{mS} / \mathrm{cm}^{2}$ \\
\hline \multirow[t]{3}{*}{$\operatorname{VIP}(n=4)$} & I & No addition & $0.051 \pm 0.009$ & $0.427 \pm 0.043$ & $1 \pm 0$ & $0.67 \pm 0.14$ \\
\hline & II & VIP & $0.051 \pm 0.005$ & $1.155 \pm 0.161^{*}$ & $22 \pm 3^{*}$ & $0.83 \pm 0.09$ \\
\hline & & $\Delta$ & $0.00 \pm 0.006$ & $0.728 \pm 0.122^{*}$ & $21 \pm 2^{*}$ & $0.16 \pm 0.08^{*}$ \\
\hline \multirow[t]{3}{*}{$\mathrm{A} 23187(n=4)$} & I & No addition & $0.039 \pm 0.004$ & $0.460 \pm 0.033$ & $1 \pm 0$ & $0.55 \pm 0.07$ \\
\hline & II & A23187 & $0.045 \pm 0.009$ & $0.964 \pm 0.146^{*}$ & $3 \pm 1^{*}$ & $0.48 \pm 0.07$ \\
\hline & & $\Delta$ & $0.006 \pm 0.012$ & $0.504 \pm 0.139^{*}$ & $2 \pm 1^{*}$ & $-0.07 \pm 0.01$ \\
\hline \multirow{3}{*}{$\begin{array}{l}\mathrm{VIP}+\mathrm{A} 23187 \\
(n=4)\end{array}$} & I & No addition & $0.040 \pm 0.007$ & $0.465 \pm 0.034$ & $1 \pm 0$ & $0.55 \pm 0.07$ \\
\hline & II & $\mathrm{VIP}+\mathrm{A} 23187$ & $0.076 \pm 0.010$ & $1.729 \pm 0.158^{*}$ & $42 \pm 4^{*}$ & $1.14 \pm 0.19^{*}$ \\
\hline & & $\Delta$ & $0.036 \pm 0.004$ & $1.264 \pm 0.131^{*}$ & $41 \pm 4^{*}$ & $0.59 \pm 0.15^{*}$ \\
\hline
\end{tabular}

The results depicted were analyzed during two time intervals: period I between 0 and $25 \mathrm{~min}$ and period II between 35 and 55 min. Within each time frame, the points were fit to straight line by the method of least squares. The slope of the line, representing the apparent rate constant for ${ }^{86} \mathrm{Rb}^{+}$efflux, is shown in the Table for both apical (mucosal) and basolateral (serosal) effluxes together with the changes in $I_{\mathrm{sc}}$ and conductances. The results are expressed as mean $\pm \mathrm{SE}$ of four experiments. The concentration of VIP was $10^{-8} \mathrm{M}$, and A23187, $0.3 \mu \mathrm{M} .{ }^{*} P<0.05$.

study we have demonstrated that the chloride secretory process induced by VIP and that induced by a calcium ionophore, A23187, potentiated each other. The effect of VIP appeared to be mediated by cAMP as supported by the VIP receptor binding assay and cAMP measurement. Comparison of the effect of VIP on ${ }^{125}$ I-VIP binding, cAMP production, and $I_{\text {sc }}$ showed that VIP binding correlated with cAMP production, and both the VIP binding and CAMP production also correlated well with the change in $I_{\text {sc }}$. These findings suggest that VIP binding stimulates cAMP production and this in turn caused an increase in $I_{\mathrm{sc}}$ (which, in this $\mathrm{T}_{84}$ epithelial model, reflected chloride secretion). In contrast, A23187 did not increase cellular cAMP production. The action of this calcium ionophore required the presence of extracellular calcium (data not shown). Presumably, chloride secretion was induced by A23187 via a calcium-dependent mechanism.

The mechanism by which VIP (cAMP) and A23187 (intracellular calcium) regulates chloride transport and the basis for their synergistic actions have been investigated in this study. Intracellular CAMP and cytosolic calcium may interact with each other or interact with other intracellular mediators that mediate or modulate their actions. On the other hand, the cAMPand calcium-dependent processes may occur independently. They may stimulate different transport pathways that happen to have cooperative interactions and are dependent on one another in the chloride secretory process. Measurement of cAMP showed that A23187 did not augment cAMP response to VIP, suggesting that A23187 potentiates the action of VIP at a step distal to the VIP binding and CAMP production. It is possible that cAMP may mobilize intracellular stores of calcium $(16,27$, 28). The role of intracellular calcium may be better elucidated in the future with the availability of fluorescent probes $(29,30)$. We have shown that VIP did not alter free cytosolic calcium (31). Unfortunately, A23187 interfered with Quin-2 fluorescent spectrofluorometry which prevented proper measurement of free cytosolic calcium in its presence. The presence of a large calcium gradient across the plasma membrane, under our experimental conditions, made increased free cytosolic calcium an unlikely mechanism by which VIP potentiated the action of A23187. However, it is possible that A23187 may have effects on the cells other than those directly associated with an increase in cytosolic calcium. These effects may be via other secondary messengers in the cell that were not measured in this study. After having shown that A23187 did not augment cAMP production by VIP, this study then sought to identify the different transport pathways activated by VIP and A23187, and to determine whether interaction at the level of the transport pathways could explain the synergistic action. The results suggest that this might be the case.

The mechanisms of chloride secretion stimulated by VIP and A23187 appear to be different, yet they share some similarity. VIP directly activates an apical membrane chloride transport pathway (25), and also increases basolateral membrane potassium efflux. Whether both pathways are regulated independently by VIP, or whether the chloride transport pathway is the primary process regulated by VIP with the increase in potassium recycling being secondary, remains to be fully elucidated. Chloride secretion induced by A23187, in contrast to VIP, appeared to be a result of an activation of the basolateral potassium efflux pathway alone. At lower concentrations of A23187, which barely produce chloride secretion, stimulation of potassium efflux was clearly evident. Direct measurement of chloride uptake and efflux, which detected the activation of the apically localized chloride transport pathway by VIP, could not detect the A23187 effect (25). We postulated that the potassium efflux across the basolateral membrane induced by A23187 hyperpolarized the cells and that this increased the driving force for chloride exit across the apical membrane. Chloride secretion occurs despite the lack of effect of A23187 on the chloride channel because some chloride channels are open randomly at any given time.

Synergism between cAMP- and calcium-mediated chloride secretion, at least in the case of VIP and A23187, appeared to be a result of their stimulation of transport pathways whose actions happen to interact cooperatively. The studies discussed above suggest that VIP and A23187 each stimulate basolateral potassium efflux, but VIP also activates an apically localized chloride conductance pathway. Utilizing ${ }^{86} \mathrm{Rb}^{+}$as a tracer for potassium, we showed that potassium efflux induced by A23187 was additive to the potassium efflux that could be stimulated by VIP. The additive responses of VIP and A23187 on potassium efflux across the basolateral membrane may be explained by 
another study that showed that the potassium efflux pathway stimulated by VIP was different from the pathway stimulated by A23187. The former was more sensitive to inhibition by barium (24). The synergistic action on chloride secretion occurred because the opening of the apically localized chloride transport pathway (by VIP) allowed the potassium efflux induced by A23187, which was a relatively ineffective driving force for chloride secretion by itself, to become an effective driving force. This driving force induced by A23187 is relatively ineffective in the absence of VIP, because the chloride exit pathway became rate limiting. According to this study, synergism is therefore a result of the cooperative interaction between the opening of the chloride exit pathway on the apical membrane and the potassium exit pathways on the basolateral membrane.

\section{Acknowledgments}

The authors express their sincere thanks and gratitude to Dr. Stephen Pandol for his invaluable aid, many helpful discussions, and critical suggestions on the cAMP measurements, part of which were carried out in his laboratory. We thank Dr. Joseph Steinbach for help with statistical analysis. Technical assistance for the project was provided by Mr. Greg Beuerlein, Mr. Dennis Lindeborg, Mr. Andrew Weymer, Mr. Ralph Finger, Mr. Joseph Preston, and Dr. Andrew Deemer. We thank Ms. Bambi Beuerlein for skillful preparation and editing of this manuscript.

This study was supported by grants R01 AM-28305 and R01 AM31619 from the National Institutes of Health, a grant from the University of California Cancer Research Coordinating Committee and a grant from the Burroughs Wellcome Fund. Dr. K. Dharmsathaphorn is the recipient of a National Institutes of Health Research Career Development Award, AM-01146, and an American Gastroenterological Association/Glaxo Research Scholar Award. Dr. C. Cartwright was supported by National Institutes of Health training grant AM-07202, a Giannini Fellowship, and a Research Training Supplement for Interdisciplinary Investigations in Gastroenterology from the American Gastroenterological Association.

\section{References}

1. Collen, M. J., V. E. Sutliff, G. Z. Pan, and J. D. Gardner. 1982. Postreceptor modulation of action of VIP and secretin of pancreatic enzyme secretion by secretagogues that mobilize cellular calcium. Am. J. Physiol. 242:G423-G428.

2. Gardner, J. D., M. D. Walker, and A. J. Rottman. 1980. Effect of A23187 on amylase release from dispersed acini prepared from guinea pig pancreas. Am. J. Physiol. 238:G458-G466.

3. Fast, D., and A. Tenenhouse. 1976. The effect of dibutyryl cyclic adenosine $3^{\prime} 5^{\prime}$-monophosphate on protein secretion in vitro. Br. J. Pharmacol. 58:605-612.

4. Singh, M. 1979. Calcium and cyclic nucleotide interaction in secretion of amylase from rat pancreas in vitro. J. Physiol. (Lond.). 296: 159-175.

5. Phang, W., L. Domboski, Y. Krausz, and G. W. G. Sharp. 1984. Mechanisms of synergism between glucose and cAMP on stimulation of insulin release. Am. J. Physiol. 247:E701-E708.

6. Soll, A. H. 1978. The interaction of histamine with gastrin and carbamylcholine on oxygen uptake by isolated mammalian parietal cells. J. Clin. Invest. 61:381-389.

7. Dharmsathaphorn, K., V. Harms, D. J. Yamashiro, R. J. Hughes, H. J. Binder, and E. M. Wright. 1983. Preferential binding of vasoactive intestinal polypeptide to basolateral membrane of rat and rabbit enterocytes. J. Clin. Invest. 71:27-35.

8. Binder, H. J., G. F. Lemp, and J. D. Gardner. 1980. Receptors for vasoactive intestinal peptide and secretin on small intestinal epithelial cells. Am. J. Physiol. 238:G190-G196.

9. Schwartz, C. J., D. V. Kimberg, H. E. Sheerin, M. Field, and S. I. Said. 1974. Vasoactive intestinal peptide stimulation of adenyl cyclase and active electrolyte secretion in intestinal mucosa. J. Clin. Invest. 54: 536-544.

10. Racusen, L. C., and H. J. Binder. 1977. Alteration of large intestine electrolye transport by vasoactive intestinal polypeptide in the rat. Gastroenterology. 73:790-796.

11. Davis, G. R., C. A. Santa Ana, S. G. Morawski, and J. S. Fordtran. 1981. Effect of vasoactive intestinal polypeptide on active and passive transport in the human jejunum. J. Clin. Invest. 67:1687-1694.

12. Dharmsathaphorn, K., J. A. McRoberts, K. G. Mandel, L. D. Tisdale, and H. Masui. 1984. A human colonic tumor cell line that maintains vectorial electrolyte transport. Am. J. Physiol. 246:G204-G208.

13. Dharmsathaphorn, K., K. G. Mandel, H. Masui, and J. A. McRoberts. 1985. VIP-induced chloride secretion by a colonic epithelial cell line: Direct participation of a basolaterally localized $\mathrm{Na}^{+}, \mathrm{K}^{+}, \mathrm{Cl}^{-}$cotransport system. J. Clin. Invest. 75:462-471.

14. Mandel, K. G., J. A. McRoberts, G. Beuerlein, E. S. Foster, and K. Dharmsathaphorn. 1985. Ba ${ }^{++}$inhibition of VIP and A23187 stimulated $\mathrm{Cl}^{-}$secretion by $\mathrm{T}_{84}$ cell monolayers. Am. J. Physiol. In press.

15. Frizzell, R. A. 1977. Active chloride secretion by rabbit colon. Calcium-dependent stimulation by ionophore A23187. J. Membr. Biol. 35:175-187.

16. Bolton, J. E., and M. Field. 1977. Ca ionophore-stimulated ion secretion in rabbit ileal mucosa: relation to actions of cyclic 3',5'-AMP and carbamylcholine. J. Membr. Biol. 35:159-173,

17. Donowitz, M. $1983 . \mathrm{Ca}^{2+}$ in the control of active intestinal $\mathrm{Na}$ and $\mathrm{Cl}$ transport: involvement in neurohumoral action. Am. J. Physiol. 245:G165-G177.

18. Weymer, A., P. Huott, J. A. McRoberts, and K. Dharmsathaphorn. 1985. Chloride secretory mechanisms induced by prostaglandin $\mathrm{E}_{1}$ in a colonic epithelial cell line. J. Clin. Invest. 76:000-000.

19. Snedecor, G. W., and W. G. Cochran. 1967. Statistical methods. 6th ed. Iowa State University Press, Ames, IA.

20. Al-Awqati, Q., and W. B. Greenough III. 1972. Prostaglandins inhibit intestinal sodium transport. Nature (New Biol.). 238:26-28.

21. Kimberg, D. V., M. Field, E. Gershon, and A. Henderson. 1974. Effects of prostaglandins and cholera exterotoxin on intestinal mucosal cyclic AMP accumulation. J. Clin. Invest. 53:941-949.

22. Zimmerman, T. W., J. W. Dobbins, and H. J. Binder. 1982. Mechanism of cholinergic regulation of electrolyte transport in rat colon in vitro. Am. J. Physiol. 242:G116-G123.

23. McRoberts, J. A., G. Beuerlein, and K. Dharmsathaphorn. 1985. Cyclic AMP and $\mathrm{Ca}^{++}$activated $\mathrm{K}^{+}$transport in a human colonic epithelial cell line. J. Biol Chem. In press.

24. McRoberts, J. A., G. Beuerlein, and K. Dharmsathaphorn. 1985. Evidence for cAMP and $\mathrm{Ca}^{++}$activated $\mathrm{K}^{+}$channels in a human colonic epithelial cell line. Fed. Proc. 44:646. (Abstr.)

25. Mandel, K. G., K. Dharmsathaphorn, and J. A. McRoberts. 1986. Characterization of a cyclic AMP-activated $\mathrm{Cl}^{-}$transport pathway in the apical membrane of a human colonic epithelial cell line. J. Biol. Chem. In press.

26. Dharmsathaphorn, K., S. Pandol, and J. A. McRoberts. 1985. $\mathrm{Cl}^{-}$secretion induced by carbachol in a human colonic cell line: studies of the mechanism of action. Gastroenterology. 88:1364. (Abstr.)

27. Juzu, H. A., and E. S. Holdsworth. 1980. New evidence for the role of cyclic AMP in the release of mitochondrial calcium. J. Membr. Biol. 52:185-186.

28. Scarpa, A., K. Malinstrom, M. Chiesi, and E. Carafoli. 1976. On the problem of the release of mitochondrial calcium by cAMP. J. Membr. Biol. 29:205-208.

29. Tsien, R. Y., T. Pozzan, and T. J. Rink. 1982. Calcium homeostasis in intact lymphocytes: cytoplasmic free calcium monitored with a new, intracellularly trapped fluorescent indicator. J. Cell Biol. 94:325334.

30. Charest, R., P. F. Blackmore, B. Berthon, and J. H. Exton. 1983. Changes in free cytosolic $\mathrm{Ca}^{2+}$ in hepatocytes following $\alpha_{1}$-adrenergic stimulation. J. Biol. Chem. 258:8769-8773.

31. Dharmsathaphorn, K., and S. Pandol. 1985. Basis for synergism between cAMP and $\mathrm{Ca}^{++}$-mediated $\mathrm{Cl}^{-}$secretion in a human colonic cell line. Gastroenterology. 88:1364. (Abștr.) 